DOI:10.15740/HAS/IJAS/15.2/263-270

Visit us : www.researchjournal.co.in

\title{
Predicting magnitude of variability and genetic divergence for yield and quality traits in tomato (Solanum lycopersicum L.)
}

\author{
Harish Chandra Badhani, Sandeep Kumar ${ }^{1}$, Amit Kumar Singh*, Satish Chandra Pant, Ajaya Paliwal and \\ Dharminder Kumar ${ }^{2}$ \\ Department of Vegetable Science, College of Horticulture, Veer Chandra Singh Garhwali Uttarakhand \\ University of Horticulture and Forestry, Bharsar, Pauri, Garhwal (Uttarakhand) India \\ (Email: amitsingh4671@gmail.com)
}

\begin{abstract}
Thirty genotypes of tomato including one check cultivar (Solan lalima) were planted in Randomized Complete Block Design, during Kharif, 2014 and were assessed to know the nature and magnitude of variability and genetic divergence for 17 horticultural traits. The experimental results revealed a wide range of variability for all the traits under study. High heritability coupled with high genetic gain was observed for marketable fruit yield (89.60 and 56.02\%), lycopene content (92.40 and 50.40\%) and buckeye rot incidence ( 80.00 and 56.12\%), which offers the better scope for improvement through selection. Based on the Mahalanobis $\mathrm{D}^{2}$ statistics, 30 genotypes of tomato were grouped into four clusters. Maximum number of genotypes were accommodated in the cluster-IV (13) followed by cluster-III (8), cluster-II (7) and I (2). Highest inter cluster distance (8.789) was recorded between cluster I and III, hence, crossing between the genotypes of these cluster is expected to yield more heterotic hybrids. On the other hand, five genotypes viz., LC-8, AVTO9001, LC-9, Punjab Chhuhara and AVTO0201 belonging to cluster-III performed better for most of the horticultural traits under study. These genotypes need further testing to be released as a substitute of already existing tomato varieties or these can be crossed with diverse genotypes of other clusters for the development of superior varieties /hybrids in tomato.
\end{abstract}

Key Words : Clusters, Diversity, Genetic variability, Quality, Tomato

View Point Article : Badhani, Harish Chandra, Kumar, Sandeep, Singh, Amit Kumar, Pant, Satish Chandra, Paliwal, Ajaya and Kumar, Dharminder (2019). Predicting magnitude of variability and genetic divergence for yield and quality traits in tomato (Solanum lycopersicum L.). Internat. J. agric. Sci., 15 (2) : 263-270, DOI:10.15740/HAS/IJAS/15.2/263-270. Copyright@ 2019: Hind Agri-Horticultural Society.

Article History : Received : 15.04.2019; Revised : 08.05.2019; Accepted : 15.05.2019

\footnotetext{
*Author for correspondence:

${ }^{1}$ ICAR-Indian Agricultural Research Institute Regional Station, Katrain, Kullu Valley (H.P.) India

${ }^{2}$ Regional Horticultural Research and Training Station (Dr.YSPUHF), Jachh, Kangra (H.P.) India
} 